\title{
Hyers-Ulam-Rassias stability of Pexiderized Cauchy functional equation in 2-Banach spaces
}

\author{
G. Zamani Eskandani ${ }^{a, *}$, P. Gavrutab \\ ${ }^{a}$ Faculty of Mathematical Science University of Tabriz, Tabriz, Iran. \\ ${ }^{b}$ Department of Mathematics, University Politehnica of Timisoara, Piata Victoriei No. 2,300006 Timisoara, Romania.
}

Dedicated to George A Anastassiou on the occasion of his sixtieth birthday

Communicated by Professor R. Saadati

\begin{abstract}
In this paper, we investigate stability of the Pexiderized Cauchy functional equation in 2-Banach spaces and pose an open problem.

copyright 2012 NGA. All rights reserved.
\end{abstract}

Keywords: Linear 2-normed space, Generalized Hyers-Ulam stability, Pexiderized Cauchy functional equation .

2010 MSC: Primary 46BXX, 39B72, 47Jxx

\section{Introduction and preliminaries}

In 1940, S.M. Ulam [34] asked the first question on the stability problem for mappings. In 1941, D. H. Hyers [14] solved the problem of Ulam. This result was generalized by Aoki [1] for additive mappings and by Th. M. Rassias [24] for linear mappings by considering an unbounded Cauchy difference. The paper of Th. M. Rassias has provided a lot of influence in the development of what we now call Hyers-UlamRassias stability of functional equations. In 1994, a further generalization was obtained by P. Găvruta [13]. During the last two decades, a number of papers and research monographs have been published on various generalizations and applications of the generalized Hyers-Ulam stability to a number of functional equations and mappings (see [5]-[12, [16]-[20], 22]-[23], [25]-[29], [32], [33]). We also refer the readers to the books: P. Czerwik [4] and D.H. Hyers, G. Isac and Th.M. Rassias [15].

In the 1960s, S. Gahler [8, 9] introduced the concept of linear 2-normed spaces.

\footnotetext{
${ }^{*}$ Corresponding author

Email addresses: zamani@tabrizu.ac.ir (G. Zamani Eskandani ), pgavruta@yahoo.com (P. Gavruta)
} 
Definition 1.1. Let $X$ be a linear space over $\mathbb{R}$ with $\operatorname{dim} X>1$ and let $\|.,\|:. X \times X \longrightarrow \mathbb{R}$ be a function satisfying the following properties:

(a) $\|x, y\|=0$ if and only if $x$ and $y$ are linearly dependent,

(b) $\|x, y\|=\|y, x\|$,

(c) $\|\lambda x, y\|=|\lambda|\|x, y\|$,

(d) $\|x, y+z\| \leq\|x, y\|+\|x, z\|$

for all $x, y, z \in X$ and $\lambda \in \mathbb{R}$. Then the function $\|.,$.$\| is called a 2-norm on X$ and the pair $(X,\|.,\|$.$) is$ called a linear 2-normed space. Sometimes the condition (d) called the triangle inequality.

It follows from (d), that $\|x+y, z\| \leq\|x, z\|+\|y, z\|$ and $|\|x, z\|-\|y, z\|| \leq\|x-y, z\|$. Hence the functions $x \longrightarrow\|x, y\|$ are continuous functions of $X$ into $\mathbb{R}$ for each fixed $y \in X$.

Lemma 1.2. ([21]) Let $(X,\|.,\|$.$) be a linear 2-normed space. If x \in X$ and $\|x, y\|=0$ for all $y \in X$, then $x=0$.

Definition 1.3. A sequence $\left\{x_{n}\right\}$ in a linear 2-normed space $X$ is called a Cauchy sequence if there are two points $y, z \in X$ such that $y$ and $z$ are linearly independent,

$\lim _{m, n \rightarrow \infty}\left\|x_{m}-x_{n}, y\right\|=0$ and $\lim _{m, n \rightarrow \infty}\left\|x_{m}-x_{n}, z\right\|=0$.

Definition 1.4. A sequence $\left\{x_{n}\right\}$ in a linear 2-normed space $X$ is called a convergent sequence if there is an $x \in X$ such that

$$
\lim _{n \rightarrow \infty}\left\|x_{n}-x, y\right\|=0,
$$

for all $y \in X$. If $\left\{x_{n}\right\}$ converges to $x$, write $x_{n} \longrightarrow x$ as $n \longrightarrow \infty$ and call $\mathrm{x}$ the limit of $\left\{x_{n}\right\}$. In this case, we also write $\lim _{n \rightarrow \infty} x_{n}=x$.

Definition 1.5. A linear 2-normed space in which every Cauchy sequence is a convergent sequence is called a 2-Banach space.

Lemma 1.6. ([21]) For a convergent sequence $\left\{x_{n}\right\}$ in a linear 2-normed space $X$,

$$
\lim _{n \rightarrow \infty}\left\|x_{n}, y\right\|=\left\|\lim _{n \rightarrow \infty} x_{n}, y\right\|,
$$

for all $y \in X$.

In [21] Won-Gil Park has investigated approximate additive mappings, approximate Jensen mappings and approximate quadratic mappings in 2-Banach spaces. In this paper, we investigate stability of the Pexiderized Cauchy functional equation in 2-Banach spaces and pose an open problem.

\section{Stability of the Pexiderized Cauchy functional equation}

Throughout this paper, let $X$ be a normed linear space, $Y$ be a 2 -Banach space with $\operatorname{dim} Y>1$ and $\mathrm{k}$ is a fixed integer greater than 1.

Theorem 2.1. Let $\varphi: X \times X \times X \longrightarrow[0,+\infty)$ be a function such that

$$
\lim _{n \rightarrow \infty} \frac{1}{k^{n}} \varphi\left(k^{n} x, k^{n} y, z\right)=0,
$$

for all $x, y, z \in X$. Suppose that $f, g, h: X \longrightarrow Y$ be mappings with $f(0)=g(0)=h(0)=0$ and

$$
\|f(x+y)-g(x)-h(y), z\| \leq \varphi(x, y, z)
$$


and

$$
\widetilde{M}_{k}(x, z):=\sum_{n=0}^{\infty} \sum_{i=1}^{k-1} \frac{M\left(k^{n} x, i k^{n} x, z\right)}{k^{n}},
$$

exist for all $x, y, z \in X$, where $M(x, y, z):=\varphi(x, y, z)+\varphi(0, y, z)+\varphi(x, 0, z)$. Then there is a unique additive mapping $A_{k}: X \longrightarrow Y$ such that

$$
\left\|f(x)-A_{k}(x), z\right\| \leq \frac{1}{k} \widetilde{M}_{k}(x, z)
$$

for all $x, z \in X$.

Proof. Replacing $y=0$ in 2.2 , we get

$$
\|f(x)-g(x), z\| \leq \varphi(x, 0, z),
$$

for all $x, z \in X$. Replacing $x=0$ in $(2.2)$, we get

$$
\|f(y)-h(y), z\| \leq \varphi(0, y, z)
$$

for all $y, z \in X$. By using (2.5) and (2.6), we get

$$
\|f(x+y)-f(x)-f(y), z\| \leq M(x, y, z),
$$

for all $x, y, z \in X$, where

$$
M(x, y, z):=\varphi(x, y, z)+\varphi(x, 0, z)+\varphi(0, y, z) .
$$

By induction on $k$, we show that

$$
\|f(k x)-k f(x), z\| \leq M_{k}(x, z),
$$

for all $x, z \in X$, where $M_{k}(x, z):=\sum_{i=1}^{k-1} M(x, i x, z)$. Letting $y=x$ in 2.7 , we get

$$
\|f(2 x)-2 f(x), z\| \leq M(x, x, z),
$$

for all $x, z \in X$. So we get 2.8 for $k=2$.

Assume that (2.8) holds for $k$. Letting $y=k x$ in 2.7), we get

$$
\|f((k+1) x)-f(x)-f(k x), z\| \leq M(x, k x, z)
$$

for all $x, z \in X$. It follows from (2.8) and 2.10$)$ that

$$
\begin{aligned}
\| f((k+1) x)- & (k+1) f(x), z \| \\
& \leq\|f((k+1) x)-f(x)-f(k x), z\|+\|f(k x)-k f(x), z\| \\
& \leq M_{k+1}(x, z),
\end{aligned}
$$

This completes the induction argument. Replacing $x$ by $k^{n} x$ in 2.8 and dividing both sides of 2.8 by $k^{n+1}$, we get

$$
\left\|\frac{1}{k^{n+1}} f\left(k^{n+1} x\right)-\frac{1}{k^{n}} f\left(k^{n} x\right), z\right\| \leq \frac{1}{k^{n+1}} M_{k}\left(k^{n} x, z\right),
$$

for all $x, y \in X$ and all non-negative integers $n$. Hence

$$
\begin{aligned}
\left\|\frac{1}{k^{n+1}} f\left(k^{n+1} x\right)-\frac{1}{k^{m}} f\left(k^{m} x\right), z\right\| & \leq \sum_{i=m}^{n}\left\|\frac{1}{k^{i+1}} f\left(k^{i+1} x\right)-\frac{1}{k^{i}} f\left(k^{i} x\right), z\right\| \\
& \leq \frac{1}{k} \sum_{i=m}^{n} \frac{1}{k^{i}} M_{k}\left(k^{i} x, z\right),
\end{aligned}
$$


for all $x, z \in X$ and all non-negative integers $m$ and $n$ with $n \geq m$. Therefore, we conclude from (2.3) and 2.12 that the sequence $\left\{\frac{1}{k^{n}} f\left(k^{n} x\right)\right\}$ is a Cauchy sequence in $Y$ for all $x \in X$. Since $Y$ is complete the sequence $\left\{\frac{1}{k^{n}} f\left(k^{n} x\right)\right\}$ converges in $Y$ for all $x \in X$. So one can define the mapping $A_{k}: X \rightarrow Y$ by:

$$
A_{k}(x):=\lim _{n \rightarrow \infty} \frac{1}{k^{n}} f\left(k^{n} x\right)
$$

for all $x \in X$. That is

$$
\lim _{n \rightarrow \infty}\left\|\frac{1}{k^{n}} f\left(k^{n} x\right)-A_{k}(x), y\right\|=0,
$$

for all $x, y \in X$. Letting $m=0$ and passing the limit $n \rightarrow \infty$ in 2.12 , we get (2.4). Now, we show that $A_{k}: X \rightarrow Y$ is an additive mapping. It follows from (2.1), (2.7), 2.13) and Lemma 1.6 that

$$
\begin{aligned}
\left\|A_{k}(x+y)-A_{k}(x)-A_{k}(y), z\right\| & =\lim _{n \rightarrow \infty} \frac{1}{k^{n}}\left\|f\left(k^{n} x+k^{n} y\right)-f\left(k^{n} x\right)-f\left(k^{n} y\right), z\right\| \\
& \leq \lim _{n \rightarrow \infty} \frac{1}{k^{n}} M\left(k^{n} x, k^{n} y, z\right)=0,
\end{aligned}
$$

for all $x, y, z \in X$. By Lemma $1.2, A_{k}(x+y)-A_{k}(x)-A_{k}(y)=0$ for all $x, y \in X$. So the mapping $A_{k}: X \rightarrow Y$ is additive.

To prove the uniqueness of $A_{k}$, let $T: X \rightarrow Y$ be another additive mapping satisfying (2.4). Then

$$
\begin{aligned}
\left\|A_{k}(x)-T(x), z\right\| & =\lim _{n \rightarrow \infty} \frac{1}{k^{n}}\left\|A_{k}\left(k^{n} x\right)-T\left(k^{n} x\right), z\right\| \\
& \leq \lim _{n \rightarrow \infty} \frac{1}{k^{n+1}} \widetilde{M}_{k}\left(k^{n} x, z\right)=0,
\end{aligned}
$$

for all $x, z \in X$. By Lemma $1.2, A_{k}(x)-f(x)=0$ for all $x, y \in X$. So $A_{k}=T$.

Theorem 2.2. Let $\psi:[0, \infty) \rightarrow[0, \infty)$ be a function such that $\psi(0)=0$ and

1. $\psi(t s) \leq \psi(t) \psi(s)$,

2. $\psi(t)<t$ for all $t>1$.

Suppose that $f, g, h: X \longrightarrow Y$ be mappings with $f(0)=g(0)=h(0)=0$ and

$$
\|f(x+y)-g(x)-h(y), z\| \leq \psi\left(\|x\|_{X}\right)+\psi\left(\|y\|_{X}\right)+\psi\left(\|z\|_{X}\right),
$$

for all $x, y, z \in X$. Then there is a unique additive mapping $A_{k}: X \rightarrow Y$ satisfying

$$
\left\|f(x)-A_{k}(x), z\right\| \leq \frac{2 \sum_{i=1}^{k-1}(1+\psi(i))}{k-\psi(k)} \psi\left(\|x\|_{X}\right)+3 \psi\left(\|z\|_{X}\right),
$$

for all $x, z \in X$. Moreover, $A_{k}=A_{2}$ for all $k \geq 2$.

Proof. Let

$$
\varphi(x, y, z)=\psi\left(\|x\|_{X}\right)+\psi\left(\|y\|_{X}\right)+\psi\left(\|z\|_{X}\right),
$$

for all $x, y, z \in X$. It follows from (1) that $\psi\left(k^{n}\right) \leq(\psi(k))^{n}$ and

$$
\varphi\left(k^{n} x, k^{n} y, z\right) \leq(\psi(k))^{n}\left(\psi\left(\|x\|_{X}\right)+\psi\left(\|y\|_{X}\right)\right)+\psi\left(\|z\|_{X}\right)
$$


By using Theorem 2.1, we can get 2.15. Now, we show that $A_{k}=A_{2}$. It follows from Theorem 2.1 that $A_{k}(x)=\lim _{n \rightarrow \infty} \frac{1}{k^{n}} f\left(k^{n} x\right)$. Replacing $x$ by $2^{n} x$ in 2.15 and dividing both sides of 2.15 by $2^{n}$, we get

$$
\begin{aligned}
\left\|\frac{f\left(2^{n} x\right)}{2^{n}}-A_{k}(x), z\right\| & \leq \frac{2 \sum_{i=1}^{k-1}(1+\psi(i))}{k-\psi(k)} \frac{\psi\left(\left\|2^{n} x\right\|_{X}\right)}{2^{n}}+\frac{3 \psi\left(\|z\|_{X}\right)}{2^{n}} \\
& \leq \frac{2 \sum_{i=1}^{k-1}(1+\psi(i))}{k-\psi(k)} \psi\left(\|x\|_{X}\right) \frac{\psi\left(2^{n}\right)}{2^{n}}+\frac{3 \psi\left(\|z\|_{X}\right)}{2^{n}}
\end{aligned}
$$

for all $x, z \in X$. By passing the limit $n \longrightarrow \infty$ in 2.16), we get $A_{k}=A_{2}$.

Theorem 2.3. Let $p, q$ be non-negative real numbers such that $p>0, q<1$ and $H:[0, \infty) \times[0, \infty) \rightarrow[0, \infty)$ be a homogeneous function of degree q. Suppose that $f, g, h: X \longrightarrow Y$ be mappings with $f(0)=g(0)=$ $h(0)=0$ and

$$
\|f(x+y)-g(x)-h(y), z\| \leq H\left(\|x\|_{X},\|y\|_{X}\right)+\|z\|_{X}^{p},
$$

for all $x, y, z \in X$. Then thereis a unique additive mapping $A_{k}: X \rightarrow Y$ such that

$$
\left\|f(x)-A_{k}(x), z\right\| \leq \frac{\sigma_{k}(H)}{k-k^{q}}\|x\|_{X}^{q}+3\|z\|_{X}^{p}
$$

for all $x \in X$, where $\sigma_{k}(H):=(k-1) H(1,0)+\sum_{i=1}^{k-1} H(1, i)+H(0, i)$. Moreover, $A_{k}=A_{2}$ for all $k \geq 2$.

Proof. Let

$$
\varphi(x, y, z)=H\left(\|x\|_{X},\|y\|_{X}\right)+\|z\|_{X}^{p}
$$

for all $x, y, z \in X$. By using Theorem 2.1, we can get (2.17). Now, we show that $A_{k}=A_{2}$. It follows from Theorem 2.1 that $A_{k}(x)=\lim _{n \rightarrow \infty} \frac{1}{k^{n}} f\left(k^{n} x\right)$. Replacing $x$ by $2^{n} x$ in 2.17) and dividing both sides of (2.17) by $2^{n}$, we get

$$
\left\|\frac{f\left(2^{n} x\right)}{2^{n}}-A_{k}(x), z\right\| \leq \frac{\sigma_{k}(H)}{k-k^{q}} \frac{\left\|2^{n} x\right\|_{X}^{q}}{2^{n}}+\frac{3\|z\|_{X}^{p}}{2^{n}}
$$

for all $x \in X$. By passing the limit $n \longrightarrow \infty$ in 2.18), we get

$$
\begin{gathered}
\lim _{n \rightarrow \infty}\left\|\frac{f\left(2^{n} x\right)}{2^{n}}-A_{k}(x), z\right\|=0, \\
\left\|\lim _{n \rightarrow \infty} \frac{f\left(2^{n} x\right)}{2^{n}}-A_{k}(x), z\right\|=0,
\end{gathered}
$$

for all $x, z \in X$. By Lemma 1.2 , $\lim _{n \rightarrow \infty} \frac{f\left(2^{n} x\right)}{2^{n}}-A_{k}(x)=0$, so $A_{k}=A_{2}$.

Theorem 2.4. Let $p, q$ be non-negative real numbers such that $p>0, q<1$ and $H:[0, \infty) \times[0, \infty) \rightarrow[0, \infty)$ be a homogeneous function of degree $q$. Suppose that $f, g, h: X \longrightarrow Y$ be mappings with $f(0)=g(0)=$ $h(0)=0$ and

$$
\|f(x+y)-g(x)-h(y), z\| \leq H\left(\|x\|_{X},\|y\|_{X}\right)\|z\|_{X}^{p},
$$

for all $x, y, z \in X$. Then there is a unique additive mapping $A_{k}: X \rightarrow Y$ such that

$$
\left\|f(x)-A_{k}(x), z\right\| \leq \frac{\sigma_{k}(H)}{k-k^{q}}\|x\|_{X}^{q}\|z\|_{X}^{p}
$$

for all $x, z \in X$, where $\sigma_{k}(H):=(k-1) H(1,0)+\sum_{i=1}^{k-1} H(1, i)+H(0, i)$. Moreover, $A_{k}=A_{2}$ for all $k \geq 2$. 
Corollary 2.5. Let $p$ be real number such that $0<p<1$. Suppose that $f, g, h: X \longrightarrow Y$ be mappings with $f(0)=g(0)=h(0)=0$ and

$$
\|f(x+y)-g(x)-h(y), z\| \leq\|x\|_{X}^{p}+\|y\|_{X}^{p}+\|z\|_{X}^{p},
$$

for all $x, y, z \in X$. Then there is a unique additive mapping $A_{k}: X \rightarrow Y$ such that

$$
\left\|f(x)-A_{k}(x), z\right\| \leq \frac{2(k-1)+2\left(1^{p}+2^{p}+\ldots+(k-1)^{p}\right)}{k-k^{p}}\|x\|_{X}^{p}+3\|z\|_{X}^{p}
$$

for all $x, z \in X$, Moreover, $A_{k}=A_{2}$ for all $k \geq 2$.

Corollary 2.6. Let $r, s, p$ be real numbers such that $p>0, r+s<1$. Suppose that $f, g, h: X \longrightarrow Y$ be mappings with $f(0)=g(0)=h(0)=0$ and

$$
\|f(x+y)-g(x)-h(y), z\| \leq\|x\|_{X}^{r}\|y\|_{X}^{s}\|z\|_{X}^{p}
$$

for all $x, y, z \in X$. Then there is a unique additive mapping $A_{k}: X \rightarrow Y$ such that

$$
\left\|f(x)-A_{k}(x), z\right\| \leq \frac{1^{s}+2^{s}+\ldots+(k-1)^{s}}{k-k^{r+s}}\|x\|_{X}^{r+s}\|z\|_{X}^{p}
$$

for all $x, z \in X$, Moreover, $A_{k}=A_{2}$ for all $k \geq 2$ and

$$
f(x)=g(x)=h(x)
$$

for all $x \in X$.

Open problem: What is the best possible value of $k$ in Corollaries 2.5 and 2.6.

\section{References}

[1] T. Aoki, On the stability of the linear transformation in Banach spaces, J. Math. Soc. Japan 2 (1950) 64-66.

[2] J. Aczél and J. Dhombres, Functional Equations in Several Variables, Cambridge University Press, 1989.

[3] Y. Benyamini and J. Lindenstrauss, Geometric Nonlinear Functional Analysis, vol. 1, Colloq. Publ., vol. 48, Amer. Math. Soc., Providence, RI, 2000.

[4] S. Czerwik, Functional Equations and Inequalities in Several Variables, World Scientific, New Jersey, London, Singapore, Hong Kong, 2002.

[5] G.Z. Eskandani, On the Hyers-Ulam-Rassias stability of an additive functional equation in quasi-Banach spaces, J. Math. Anal. Appl. 345 (2008) 405-409.

[6] G. Z. Eskandani, P. Gavruta, J. M. Rassias, and R. Zarghami, Generalized Hyers-Ulam stability for a general mixed functional equation in quasi- $\beta$-normed spaces,. Mediterr. J. Math. 8 (2011), 331-348.

[7] G.Z. Eskandani, H. Vaezi and Y.N. Dehghan, Stability of mixed additive and quadratic functional equation in non-Archimedean Banach modules, Taiwanese J. Math. 14 (2010) 1309-1324.

[8] S. Ghler, 2-metrische Rume und ihre topologische Struktur, Math. Nachr. 26 (1963) 115-148.

[9] S. Ghler, Lineare 2-normierte Rumen, Math. Nachr. 28 (1964) 1-43.

[10] L. Găvruta, P. Găvruta and G.Z.Eskandani, Hyers-Ulam stability of frames in Hilbert spaces, Bul. Stiint. Univ. Politeh. Timis. Ser. Mat. Fiz. 55(69), 2 (2010) 60-77.

[11] P. Găvruta, On a problem of G. Isac and Th. M. Rassias concerning the stability of mappings, J. Math. Anal. Appl. 261 (2001), 543-553.

[12] P. Găvruta, An answer to question of John M. Rassias concerning the stability of Cauchy equation, Advanced in Equation and Inequality (1999) 67-71.

[13] P. Găvruta, A generalization of the Hyers-Ulam-Rassias stability of approximately additive mappings, J. Math. Anal. Appl. 184 (1994) 431-436.

[14] D. H. Hyers, On the stability of the linear functional equation, Proc. Nat. Acad. Sci. 27 (1941), $222-224$.

[15] D. H. Hyers, G. Isac and Th. M. Rassias, Stability of Functional Equations in Several Variables, Birkhäuser, Basel, 1998.

[16] S. M. Jung, Hyers-Ulam-Rassias Stability of Functional Equations in Mathimatical Analysis, Hadronic Press, Palm Harbor, 2001.

[17] S. M. Jung, Asymptotic properties of isometries, J. Math. Anal. Appl. 276 (2002) 642-653. 
[18] Pl. Kannappan, Quadratic functional equation and inner product spaces, Results Math. 27 (1995), 368-372.

[19] A. Najati and G.Z. Eskandani, Stability of a mixed additive and cubic functional equation in quasi-Banach spaces, J. Math. Anal. Appl. 342 (2008) 1318-1331.

[20] C. Park, Homomorphisms between Poisson JC ${ }^{*}$-algebras, Bull. Braz. Math. Soc. 36 (2005), 79-97.

[21] W.G. Park, Approximate additive mappings in 2-Banach spaces and related topics, J. Math. Anal. Appl. 376 (2011) 193-202.

[22] J.M. Rassias, On approximation of approximately linear mappings by linear mappings, Journal of Functional Analysis, vol. 46, no. 1, pp. 126-130, 1982.

[23] J. M. Rassias, On approximation of approximately linear mappings by linear mappings, Bulletin des Sciences Mathematiques, vol. 108, no. 4, pp. 445-446, 1984.

[24] Th.M. Rassias, On the stability of the linear mapping in Banach spaces, Proc. Amer. Math. Soc. 72 (1978), $297-300$.

[25] Th.M. Rassias, On a modified Hyers-Ulam sequence, J. Math. Anal. Appl. 158 (1991) 106-113.

[26] Th.M. Rassias, On the stability of functional equations in Banach spaces, J. Math. Anal. Appl. 251 (2000) $264-284$.

[27] Th.M. Rassias, On the stability of functional equations and a problem of Ulam, Acta Appl. Math. 62 (1) (2000) 23-130.

[28] Th.M. Rassias and P. Šemrl, On the behaviour of mappings which do not satisfy HyersUlam stability, Proc. Amer. Math. Soc. 114 (1992) 989-993.

[29] Th.M. Rassias and J. Tabor, What is left of Hyers-Ulam stability?, J. Natural Geometry, 1 (1992), 65-69.

[30] K. Ravi, M. Arunkumar and J. M. Rassias, Ulam stability for the orthogonally general Euler-Lagrange type functional equation, Intern. J. Math. Stat. 3 (A08)(2008) , 36-46.

[31] S. Rolewicz, Metric Linear Spaces, PWN-Polish Sci. Publ., Warszawa, Reidel, Dordrecht, 1984.

[32] R. Saadati, Y.J. Cho and J. Vahidi, The stability of the quartic functional equation in various spaces, Comput. Math. Appl. (2010) doi:10.1016/j.camwa.2010.07.034.

[33] R. Saadati, S.M. Vaezpour, Y. Cho, A note on the On the stability of cubic mappings and quadratic mappings in random normed spaces, J. Inequal. Appl. (2009). Article ID 214530.

[34] S.M. Ulam, A Collection of the Mathematical Problems, Interscience Publ. New York, (1960),431-436. 